\title{
Efficiency indicators of the eastern polygon and its development prospects
}

\author{
Natalya N. Grigoryeva ${ }^{1, *}$, and Tatyana A. Bulokhova ${ }^{1}$ \\ ${ }^{1}$ Irkutsk State Transport University, 15, Chernyshevsky Str., Irkutsk, Russia
}

\begin{abstract}
The development strategy of "Russian Railways" OAO provides for increasing competitiveness and strengthening the company's market position. Due to the increase in Russia's foreign trade turnover with the countries of the Asia-Pacific region, the growth of transit freight traffic between Europe and Asia, and the need to implement the country's transit potential in the context of the globalization of the transport service market the railway industry faces the task of handling the growing volumes of traffic in the direction of the Far Eastern ports. One of the essential goals until 2030 is to increase the country's transit capacity. Its implementation is a priority in the field of international standing of our country. Along with the BaikalAmur Mainline, the Eastern polygon is pivotal in solving this problem. Its development will ensure the connection of transport flows from West to East, will make changes in the routes of world trade, thereby increasing the share of Russia in Eurasian transit. The degree of efficient railway transport operation depends on the creation of favorable conditions for modernization, transition to the innovative development path and sustainable growth of the national economy. This generally contributes to the conditioning of Russia's leadership in the world economic system, as there is a new geopolitical landscape globally evolving at present, whose contours should be considered in the foreseeable future. In today's conditions of railway management, it is impossible to head over to an innovative path without proper infrastructure development, affecting the performance of structural units and requiring investments.
\end{abstract}

Keywords: reformation, transit potential, polygon technologies

\section{Introduction}

In the Russian transport system, railways have a leading role characterized by long transportation distances, the lack of communication of other types of transport in the direction of East-West, primarily in the regions of Siberia and the Far East, by spatial disintegration of production and consumption of basic raw materials. A significant increase in the volume of traffic from the West Siberian Railway [8] to the ports of the Far East resulted in the need for structural changes in the field of traffic management of the Krasnoyarsk, East Siberian, Transbaikal and Far Eastern railways. They have common technological features (origination (dissipation) of freight traffic volumes, provision of traction service, logistic management of the delivery to seaports and interstate division points, etc.) and infrastructure parameters (in particular, the Eastern polygon).

The Eastern polygon, located within the boundaries of 4 railways - Krasnoyarsk, East Siberian, Transbaikal, and Far East - serves the transport needs of 14 constituent entities of the Russian Federation and the transit needs of the country (Grigoryeva, 2020).

\section{Problem Statement}

Today, as with the origination of Russian railways, the main remaining problem is the chronic shortage or complete lack of technological infrastructure reserves due to the extremely high network load and its negative impact on the quality of customer service. The targeted work, carried out at "Russian Railways" OAO to organize and plan train traffic on the network polygons (instead of regional management principles), is aimed at ensuring the growth of freight turnover, passenger turnover and indicators of quality operation performance [7]. At the same time, the basis of the polygon technology, consisting of uniform principles of car and locomotive fleet and infrastructure management, requires the development of the entire production complex, for the needs of which investments are required.

\section{Research Questions}

At the current stage of development, the polygon technologies have proved to be positive in the organization and direct management of the transportation process of rail transport.

* Corresponding author: zolotkina@mail.ru 
Today the Eastern polygon, formerly the first pilot project, clearly proves its effective functioning.

Implementation of the transport management model on four roads allows one to organize and control car and train traffic, based on the feasibility not only of the economic criteria set by the interests of the Holding as a whole. This creates the possibility of moving to a technology-linked framework in the rationalization of train traffic management and makes it possible:

- to increase the operation efficiency by improving the handling of the transportation process;

- to improve the quality of planning and organization of "track possessions" and long-term shutting-downs for infrastructure repairs;

- to increase the length of runs and sections within which the technically safe passage of cars between train service points is guaranteed;

- to improve the quality of service for rail transport users [9];

- to ensure a rational organization of working hours and rest period of locomotive crews [6].

\section{Purpose of the Study}

The purpose of this article is to analyse the performance of the Eastern polygon and its future development through investment in its infrastructure.

\section{Research Methods}

Since 2012, the effectiveness of polygon technologies has been proven not only by real-time work indicators, but also by locomotive crew organization indicators, which are steadily improving.

During the study period, the operating volume increased by $27 \%$ (Figure 1). With a relatively small increase in the work force of locomotive crews $(2.5 \%)$ (Figure 2), overtime hours are reduced by $46 \%$ (Figure 3) and hours of non-productive losses have been reduced by $15 \%$ (Figure 4 ).

Since 2012, the average daily capacity of the working fleet locomotives at the polygon has increased by $15.3 \%$ (Figure 5). This result was achieved by driving fullweight and full-length trains.

The growth of the average train weight (Figure 06) by $3.2 \%$ and the average daily kilometerage of the locomotive (Figure 7) by $6.1 \%$ also had a positive effect on the locomotive performance.

The reasons for the average train weight growth were the increase in the average train length and the decrease in the percentage of empty kilometerage.

The service speed depends on the throughput capacity of separate sections, the amount of freight and passenger train traffic, the technical condition of the track, block service and rolling stock, train schedule and centralized traffic control. This, in turn, had a positive impact on its tendency (Figure 8).

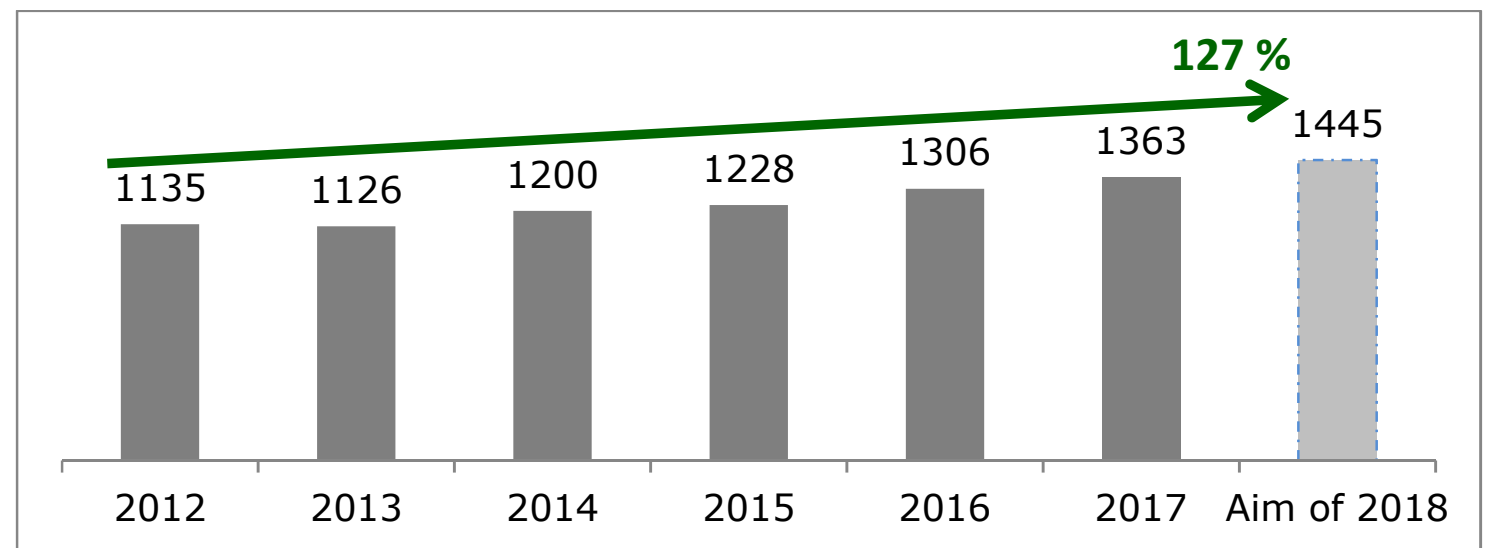

Figure 01. The amount of work in the billions of km, gross

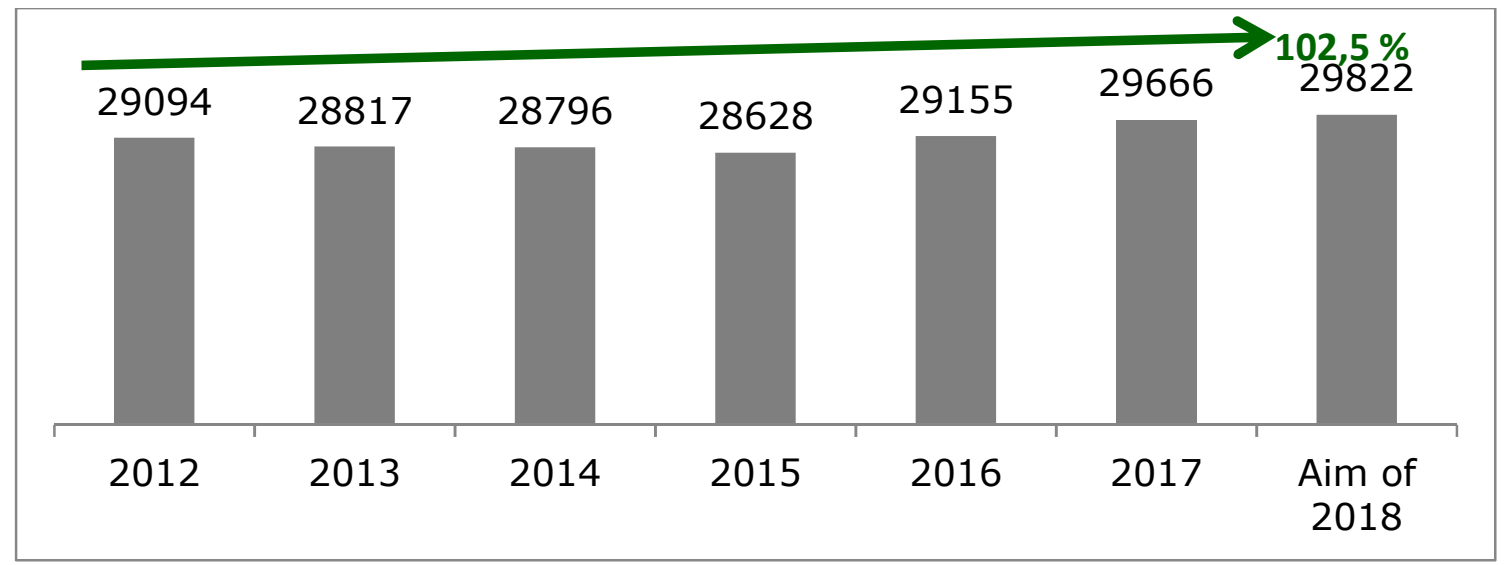

Figure 02. Average listed work force, pers 


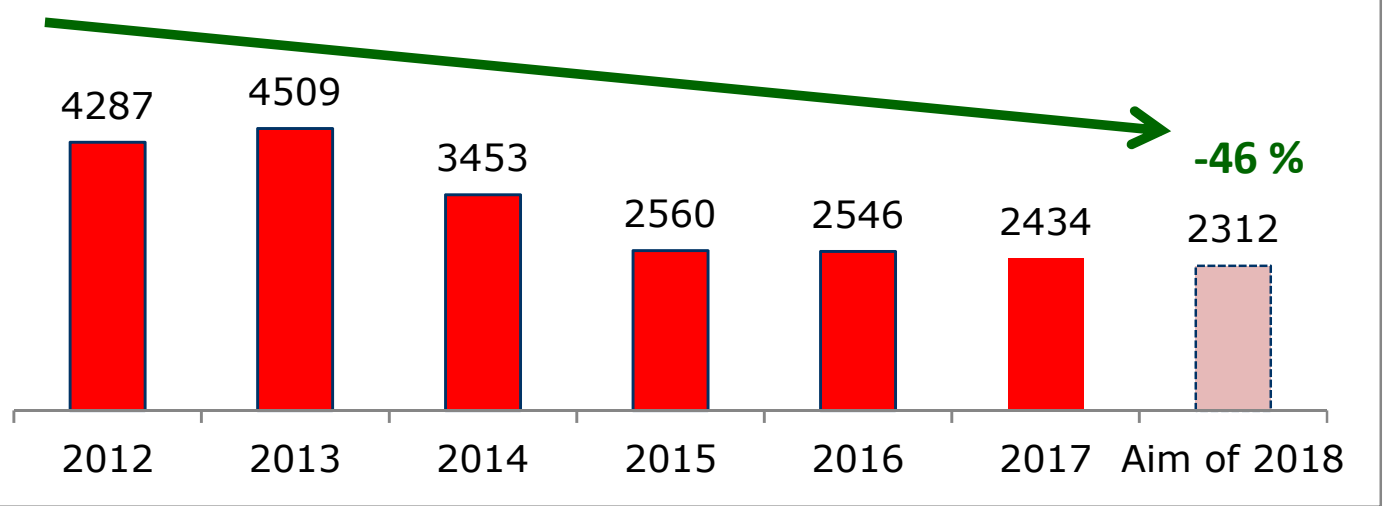

Figure 03. Overtime work, hrs

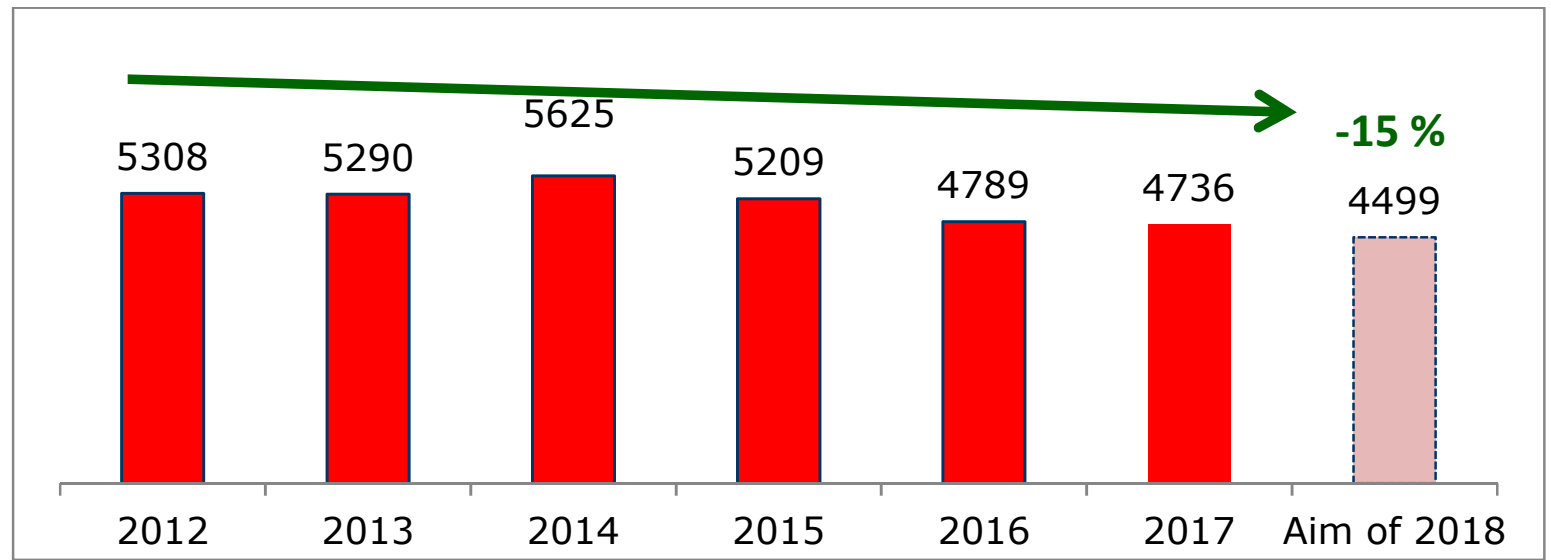

Figure 04. Non-productive losses, thousands of hours

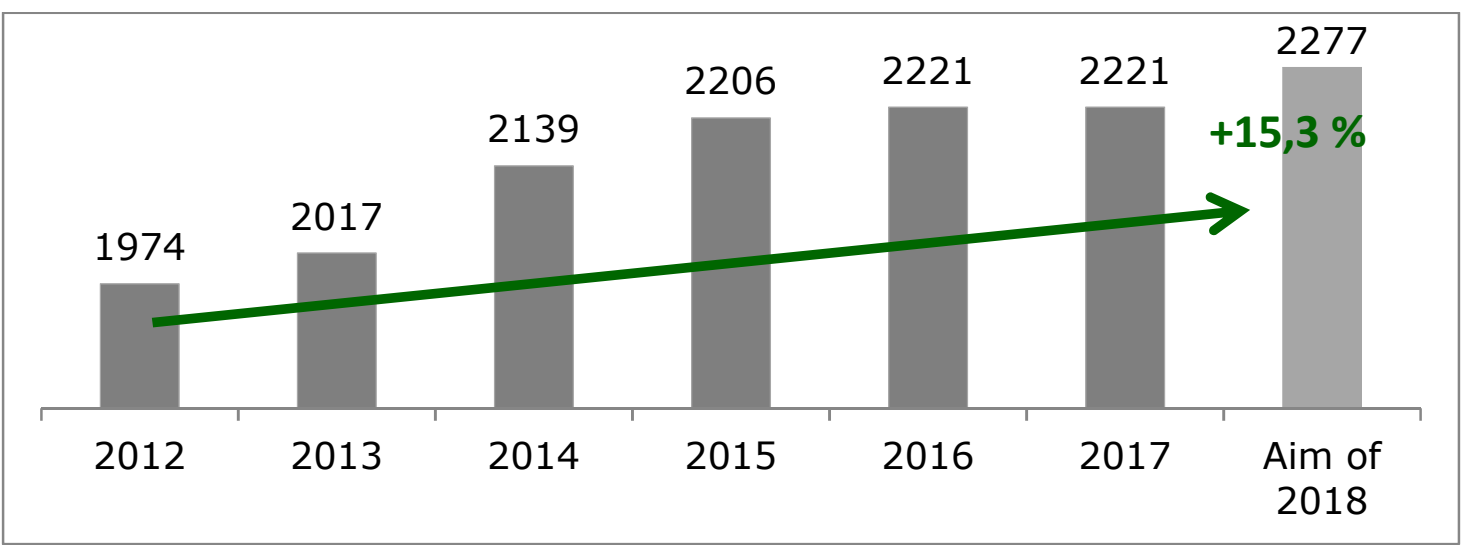

Figure 05. Average daily performance, thous. km, gross

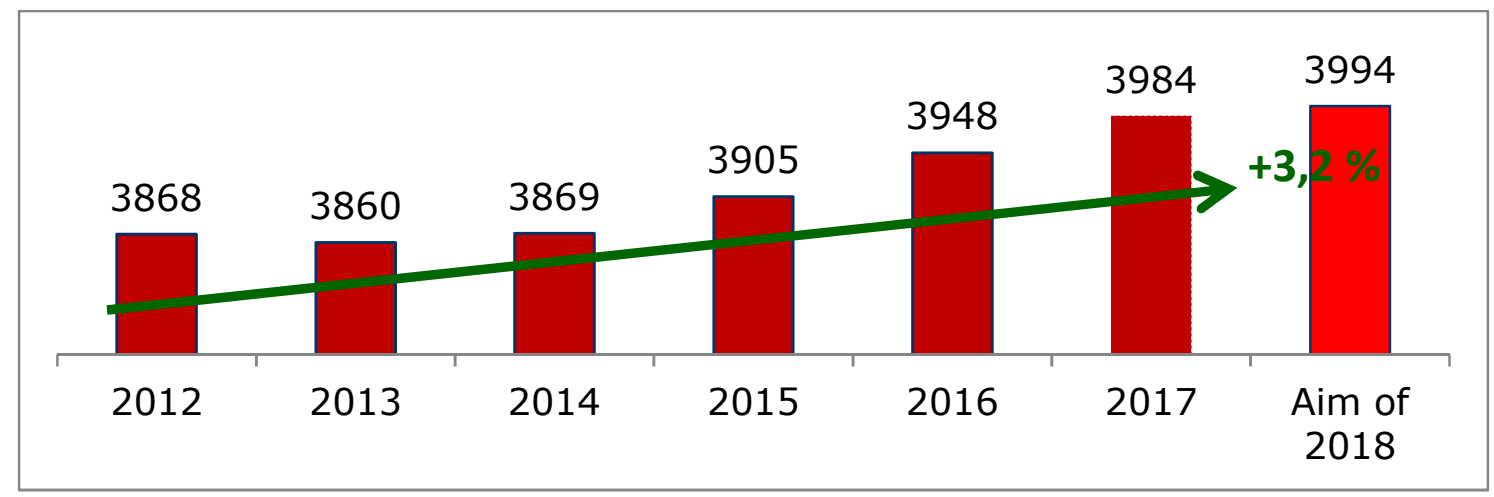

Figure 06. Average train weight, $\mathrm{t}$ 


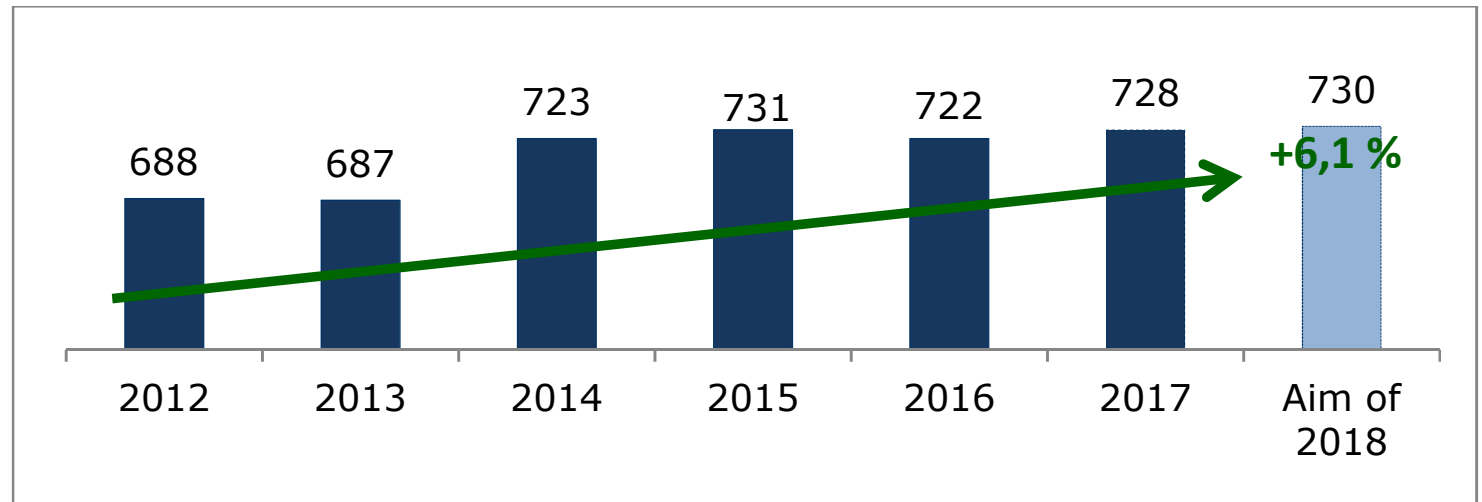

Figure 07. Average daily kilometerage, km

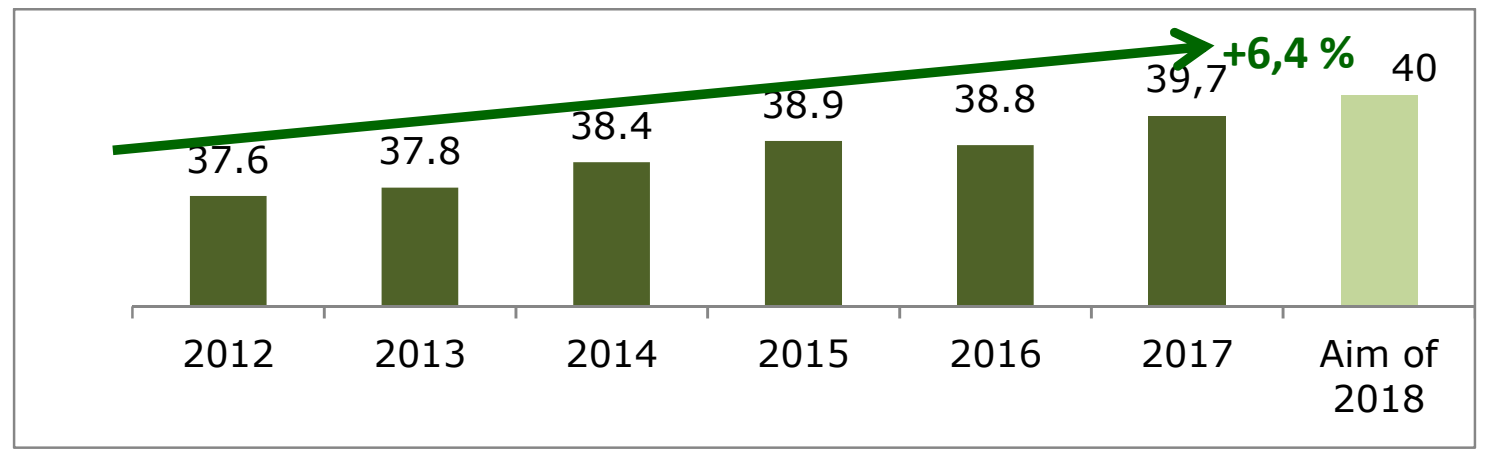

Figure 08. Service speed, $\mathrm{km} / \mathrm{h}$

The introduction of uniform parameters of train work at the Eastern polygon and its traction maintenance, carried out under the management of the Eastern Polygon Freight Control Center, allows one to implement the principles of technological interaction of all participants in the transportation process on the problems of:

- long-term and real-time planning of transportation process (in accordance with the railway production activities (regional corporate management centres), directorates, railway rolling stock operators and owners of non-public tracks);

- standardizing of transportation process;

- real-time control of the technological standard implementation, including the speed of car traffic volume and train traffic movement;

- dispatching real-time management of the transportation process;

- information support of interaction.

One of the main functions of the Eastern Polygon Freight Control Center is to ensure the logistics of transporting foreign trade goods by appointment to the ports and border crossings of the Far Eastern Railway. The largest Far Eastern ports account for a quarter of the cargo turnover of Russian ports [5].

Logistic support of transportation within the boundaries of the Eastern polygon is one of the most important functions of polygon technology. The main task is to monitor the car traffic volumes to the Eastern polygon at inter-road division points and to create proposals for the standardization of the presence of cars on the polygon roads and the amount of their handover at the Arkhara and Khan junctions to port stations and oil depots.
The concentration of this work in the Eastern Polygon Freight Control Center will not only make it possible to arrange the rhythmic supply of trains to ports, but also to significantly increase the train traffic progress prediction depth on the Eastern polygon transit roads, starting from the freight traffic origination.

Currently, the Trans-Siberian railway and the BaikalAmur mainline's throughput capacity is more than 100 billion tons and will be additionally increased by 65 million tons in the coming years. However, such results can only be achieved by increasing the investment attractiveness of the transport and logistics sectors [4].

For example, the volume of the investment program of the East Siberian Railway, which is part of the Eastern polygon, amounted to 42.8 billion rubles in 2017 (this is $7.8 \%$ more than in 2016). At the end of the two-year period of 2016-2017, 91 facilities were commissioned on the Eastern polygon development project [2].

In 2018, about 57 billion rubles were provided to implement the investment program of Russian Railways OAO within the borders of the Eastern Siberian Railway. Most of the money is used to modernize the railway infrastructure of the Baikal-Amur and Trans-Siberian Mainlines to increase the carrying and throughput capacity of the road. Investments in the development of the East Siberian Railway in 2019 amounted to 54 billion rubles. In 2019, the total volume of repair and track work on the East Siberian Railway was $406.8 \mathrm{~km}$. Within the framework of the campaign, the track was reconstructed for more than $232 \mathrm{~km}$ : on the sections of the Trans-Siberian $(130.4 \mathrm{~km})$ and the Baikal Amur Mainline $(102.3 \mathrm{~km}), 170 \mathrm{~km}$ of full and intensive medium repairs were carried out. The continuous or 
"velvet smooth" track has been laid on 38 sections of the mainline with a total length of $340.9 \mathrm{~km}$. Thus, over the past three years, the amount of investment in infrastructure upgrades on the East Siberian Railway has increased [1].

As a result of the renewal of infrastructure facilities, it was possible to reduce the duration of sections with existing speed limits by $21 \%$, to reduce the length of barrier locations by $6.5 \%$.

\section{Conclusion}

Thus, the development and renewal of the railway infrastructure is a prerequisite for ensuring the balanced economic development of the Eastern polygon and the country as a whole, forming an internal production base, implementing industrial potential, expanding foreign economic ties and ensuring the integrity and security of the state.

\section{Acknowledgments}

The research "Improving interaction mechanisms between polygon structures and regional corporate governance centers as illustrated by the Eastern Railway Polygon of Russian Railways OAO" was publicly funded.

\section{References}

1. T.A. Bulokhova, A.S. Peretolchina. The level of development of the railway infrastructure as a factor in ensuring the industry customer focus and the sustainable development of the regions. In: The development of economic science in transport: the economic basis for the future of transport systems (pp. 147-154) (Inst. of Independent Soc. and Econ. Stud. OOO, St. Petersburg, 2019)

2. T.A. Bulokhova. Modeling the quality of public transport services. Modern Technol. Syst. anal. Model., 1(65), 128-136 (2020)

3. N.N. Grigoryeva. Railway transport management system transformation in passing to polygon technologies. IOP Conf. Ser. Mat. Sci. and Eng. 918, $012194 \quad$ (2020). DOI: $10.1088 / 1757$ 899X/918/1/012194

4. N.N. Grigoryeva. The Problems and the Future of Implementing Innovations in Railway Transport. Transport infrastructure of the Siberian region. The mat. of 9th Int. sci. and pract. conf., vol. 2 (ISTU, Irkutsk, 2018), pp. 97-101

5. V.A. Olentsevich, V.E. Gozbenko, S.K. Kargapoltsev. Automated system for placing and securing cargo on open rolling stock of railway transport. Bull. of Irkutsk State Techn. Univ., 21, 157-165 (2017)

6. V.A. Olentsevich, N.P. Astashkov, Yu.I. Belogolov. Improvement of Transport Processes Operational Management on Railway Transport. Proceedings of $6^{\text {th }}$ International Symposium on Innovation and
Sustainability of Modern Railway ISMR 2018 (ISTU, Irkutsk, 2018), pp. 602-609

7. V.E. Kautz, E.V. Nefedieva. Innovations in the transportation process by the example of the East Siberian Railway and the Eastern Polygon of the Trans-Siberian Railway. In: The Transport Infrastructure of the Siberian Region, vol. 2 (pp. 120-124) (IrGUPS, Irkutsk, 2019)

8. O.I. Mokretsova, Yu.N. Malanina, N.V. Kretova, A.A. Zaikovskaya, I.R. Libenson. Governmental Support and Efficiency Management of JSC "Russian Railways" Investment Activity. In: Advances in Economics, Business and Management Research. Vol. 113. Factors of Regional Extensive Development (FRED 2019) (2019). Retrieved from http://creativecommons.org/licenses/by-nc/4.0/

9. G.V. Silicheva, T.A. Bulokhova, E.S. Podgornova. Methodological approaches to quality management in railway transport in the context of industry reform (IrGUPS, Irkutsk, 2016) 